\title{
The fight against tobacco
}

This issue of Monaldi Archives for Chest Diseases - Respiratory Series -, the first of 2013, is almost entirely dedicated to papers dealing with the fight against tobacco and its deleterious effects on human health, particularly on respiratory health.

Along the last 10 years our Journal published many reports on this important if not crucial issue inside the section denominated "Tobacco Pouch". This issue is thus to be seen as a ... bigger Tobacco Pouch, one that can possibly contain an up to date of the huge burden of problems that tobacco smoke poses to each and every one of the Health Systems throughout the world.

The fight against tobacco can start from an educational approach addressed to school children, as it is described in the Di Paco article [1] where the Authors evaluated their educational strategy in a cohort of school children. Another important point is the fight against exposure of tobacco smoke of "innocent bystanders" as people living, working in indoor environment shared with smokers can be somehow defined. Ferrante and Coll. described this last frontier of the fight against tobacco [2]. This fight is of course firstly addressed to smokers (i.e. first hand smoke), to people who live and work with smokers, while they smoke (second hand smokers) but also to people, including infants, babies, children and adolescents, living in houses or anyhow sharing indoor ambient air with smokers who smoke when they are not present (third hand smoke). The combination of tobacco smoke pollutants which remain in an indoor environment, the so-called 'third-hand smoke', represent a new concept in the field of tobacco control.

Once the smoking habit is already in place, different strategies can be adopted to get smokers to quit. Pharmacological approaches have been proved successful but only in a minority of smokers, as the article by Santus et al review [3]. Even more difficult is the approach to patients with COPD who, despite appropriate advice and counseling, do not quit. Jimenez Ruiz reviewed for us the pharmacological and counseling strategies to be used in these difficult cases $[4,5]$.

Last but not least, we decided to include also an article on the controversial yet currently heavily present in the news of the so called "electronic cigarettes" or Electronic Nicotine Delivery Systems (ENDS) [6]. In our Country, as the accompanying Editorial of Stefano Nardini points out [7] ENDS are becoming a big issue for many reasons. Commercial interest, lack of clear indications from the Health Authorities related to the lack of any certain evidence on their effects, poor knowledge by the vast majority of Physicians on this topic are just some of the many faces of the problems related to the diffusion in the last two years of ENDS in Italy. In this context, we decided to publish the article by Caponnetto et al [6], knowing that this is a controversial issue, that there are conflicting interests between the need for more research and the current wide use of ENDS. Certainly Monaldi is not sponsoring any strategy that involves the use of ENDS of any brand before a clear indication is released by National and International Regulatory Agencies. We just wanted our Journal to deal somehow with this problem to raise the interest of our readers on the many questions that our patients are asking to us every day.

Finally a word of gratitude to Stefano Nardini who helped us with a great deal of work in this enterprise. Without his commitment this "Big Tobacco Pouch" issue of Monaldi simply would not be available to our readers.

\author{
Bruno Balbi \\ Divisione di Pneumologia Riabilitativa \\ Fondazione Salvatore Maugeri, I.R.C.C.S. \\ Veruno (NO), Italy
}

\author{
Antonio Spanevello \\ Divisione di Pneumologia Riabilitativa \\ Fondazione Salvatore Maugeri, I.R.C.C.S. \\ Tradate (VA) and University of Insubria, Varese, Italy
}

\section{References}

1. Di Paco A, et al. A sequential school based smoke prevention program in secondary school adolescents. Monaldi Arch Chest Dis 2013; 79: 8-11.

2. Ferrante G, et al. Third-hand smoke exposure and health hazards in children. Monaldi Arch Chest Dis 2013; 79: 38-43.

3. Santus P, et al. Varenicline and evaluated outcomes in smoking cessation programmes. Monaldi Arch Chest Dis 2013; 79: 20-26.
4. Jiménez-Ruiz CA, et al. Smoking cessation treatment for COPD smokers: the role of pharmacological interventions. Monaldi Arch Chest Dis 2013; 79: 27-32.

5. Jiménez-Ruiz CA, et al. Smoking cessation treatment for COPD smokers: the role of counselling. Monaldi Arch Chest Dis 2013; 79: 33-37.

6. Caponnetto P, et al. Electronic cigarette: a possible substitute for cigarette dependence. Monaldi Arch Chest Dis 2013; 79: 12-19.

7. Nardini S, et al. E-cigarettes, smokers and health policies. Monaldi Arch Chest Dis 2013; 79: 6-7. 